\title{
Association Between Alterations in theSerum 25-Hydroxyvitamin D Status During Follow-Up and Breast Cancer Patient Prognosis
}

\author{
Seung Taek Lim¹, Ye Won Jeon², Young Jin Suh'*
}

\begin{abstract}
Background: Serum vitamin D status can affect the prognosis of breast cancer patients. Our aim was to determine the association between alterations in the 25-hydroxyvitamin $D$ [25(OH)D] status during follow-up and the prognosis of breast cancer patients. Additionally, we evaluated the association between the 25( $\mathrm{OH}) \mathrm{D}$ status at the time of diagnosis and the prognosis using a detailed age and stage categorization. Materials and Methods: Four hundred and sixty-nine Korean breast cancer patients were included. We collected patient clinicopathological data, including their serum $25(\mathrm{OH}) \mathrm{D}$ concentration at diagnosis and at the annual followup until 4 years after diagnosis. The patients were divided according to their $25(\mathrm{OH}) \mathrm{D}$ status at diagnosis into a deficient $(<20 \mathrm{ng} / \mathrm{ml})$ and a non-deficient $(\geq 20 \mathrm{ng} / \mathrm{ml})$ group. At follow-up, patients were categorized into the four following groups according to $25(\mathrm{OH}) \mathrm{D}$ status alterations: persistently deficient, improved, deteriorated and persistently non-deficient. Results: At diagnosis, 118 patients were classified into the deficient group and 351 into the non-deficient group. After a median follow-up period of $85.8 \pm 31.0$ months, the patients with advancedstage disease or an older age in the non-deficient group showed a significantly better survival compared with the deficient group. Furthermore, at the 1-year follow-up of 25(OH)D status, the persistently non-deficient group and the improved group had better survival compared with the other two groups. Conclusions: Our results suggest that maintaining an optimal 25(OH)D status at diagnosis and during the 1-year follow-up period is important for improving breast cancer patient survival.
\end{abstract}

Keywords: Breast cancer - 25-hydroxyvitamin D - follow-up - Survival

Asian Pac J Cancer Prev, 16 (6), 2507-2513

\section{Introduction}

The anticarcinogenic properties of vitamin $\mathrm{D}$, such as inhibiting cell proliferation and promoting apoptosis and cell differentiation in breast cancer, have been shown in several studies (Carlberg, 2003; Holick, 2006; Holick, 2009). Additionally, the importance of vitamin D in breast cancer epidemiology is being steadily revealed. In humans, most vitamin $\mathrm{D}$ is obtained in the form of vitamin D3 (cholecalciferol) from the skin upon exposure to ultraviolet B solar radiation. Vitamin D3 is transported to the liver and undergoes hydroxylation to form 25-hydroxyvitamin D [25(OH)D], the major circulating form of vitamin D. Subsequently, a second hydroxylation of $25(\mathrm{OH}) \mathrm{D}$ occurs in the kidneys and breast tissues to create 1.25 -dihydroxyvitamin $\mathrm{D}$, the active form of vitamin D (Bikle, 2009). The serum 1.25-dihydroxyvitamin $\mathrm{D}$ level does not provide a credible reflection of an individual's vitamin D status because of its short half-life and unmeasurable local production. Therefore, the serum 25(OH)D level is currently accepted as a better indicator of an individual's vitamin D status (Iqbal, 1994; Jacob et al., 2008; Crew et al., 2009). Several studies have reported that the serum $25(\mathrm{OH}) \mathrm{D}$ status is associated with breast cancer risk, stage and patient age (Palmieri et al., 2006; Alipour et al., 2014; Shi et al. 2014).

To date, several studies have investigated the association between serum $25(\mathrm{OH}) \mathrm{D}$ status and breast cancer patient survival (Kermani et al., 2011). Although the results are conflicting, most of the studies reported a significant association between the serum 25(OH)D status and survival. For example, in 2009, Goodwin et al. reported that breast cancer patients with low $25(\mathrm{OH})$ D levels $(<20 \mathrm{ng} / \mathrm{ml})$ had poorer outcomes for long-term disease-free survival and overall survival compared with patients with an optimal $25(\mathrm{OH}) \mathrm{D}$ status $(>28.8 \mathrm{ng} / \mathrm{ml})$, as assessed with univariate analysis (Goodwin et al., 2009). Recently, in 2013, Villasenor et al. reported better overall survival in a $25(\mathrm{OH}) \mathrm{D}$ sufficient $(>30 \mathrm{ng} / \mathrm{ml})$ group compared with a $25(\mathrm{OH}) \mathrm{D}$ deficient $(<20 \mathrm{ng} / \mathrm{ml})$ group (Villasenor et al., 2013). Because of these reports, the interest in $25(\mathrm{OH}) \mathrm{D}$ status for breast cancer prognosis has notably increased.

Despite these significant results, the previous studies presented several limitations. First, a single measurement of the $25(\mathrm{OH}) \mathrm{D}$ concentration was performed. The $25(\mathrm{OH}) \mathrm{D}$ status can change after a breast cancer diagnosis for many reasons, such as adjuvant chemotherapy, life- 
style modifications, or vitamin D supplementation (Kim et al., 2014; Vance et al., 2014; Heaney et al., 2003). It is plausible that alterations in the $25(\mathrm{OH}) \mathrm{D}$ status during the follow-up period might affect a breast cancer patient's prognosis, including the risks of recurrence, metastasis and death. However, none of the currently available reports overcame this limitation, most likely due to the lack of follow-up data. The second limitation is that all the subjects included in previous studies, except those from the study of Kim et al. (Kim et al., 2011), were weighted toward westerners. Ethnic differences must be considered in the analysis of serum $25(\mathrm{OH}) \mathrm{D}$ concentrations and breast cancer pathophysiologies (McCullough et al., 2010). For instance, the median age at diagnosis of Asian breast cancer patients is younger than the median age of their western counterparts (Mousavi-Jarrrahi et al., 2013). Furthermore, because of the traditions of oriental cultures, the amount of sunlight exposure in Asian populations is lower compared with Western populations (Lee et al., 2009; Kim et al., 2010). However, the only previous report concerning an Asian population had limited power to evaluate the effect of the $25(\mathrm{OH}) \mathrm{D}$ status at the time of diagnosis on survival because of the relatively small sample size $(n=310$, including patients with ductal carcinoma in situ (DCIS) and the short-term nature of the follow-up (23 months).

Therefore, in this study, we collected data on the $25(\mathrm{OH}) \mathrm{D}$ status in Korean breast cancer patients at the time of diagnosis and at the annual follow-up for 4 years. Our primary aim was to determine the association between alterations in the $25(\mathrm{OH}) \mathrm{D}$ status during follow-up and the prognosis of breast cancer patients. Additionally, we evaluated the association between the $25(\mathrm{OH}) \mathrm{D}$ status at the time of diagnosis and the prognosis using detailed age and stage categorization.

\section{Materials and Methods}

\section{Study participants}

In this study, we retrospectively reviewed the medical records of 491 Korean women with breast cancer diagnosed at St. Vincent hospital between january 2000 and december 2008. The analysis included women aged 18-90 years old at the time of diagnosis who were histologically confirmed with primary invasive (stage I-IIIc) breast cancer after surgery. We excluded the patients who had metastatic disease at the time of breast cancer diagnosis, had a history of previous malignancy, or had undergone neoadjuvant chemotherapy. Patients who lacked data on the serum $25(\mathrm{OH}) \mathrm{D}$ concentration at diagnosis were also excluded. After exclusion, 469 patients were included in the final study. All patients who were at risk for relapse received adjuvant chemotherapy followed by local radiotherapy and/or hormonal therapy according to the recommended therapeutic regimen at the time of surgery as determined by international guidelines, such as the national comprehensive cancer network (NCCN). This study was approved by the institutional review board of St. Vincent hospital.
The serum $25(\mathrm{OH}) \mathrm{D}$ concentration at diagnosis was determined for all of the patients using a blood sample drawn after breast cancer surgery but before adjuvant treatment (on average, within 6.58 days after surgery). The serum samples were stored in aliquots at $-80^{\circ} \mathrm{C}$ until analysis and the serum concentration of $25(\mathrm{OH})$ D was measured by chemiluminescent microparticle immunoassay using the ARCHITECT-i system (abbott diagnostics). The intra-assay coefficient of variation was $10 \%$. The follow-up serum $25(\mathrm{OH}) \mathrm{D}$ concentration was determined annually in the same manner, until 4 years after the diagnosis of breast cancer. Although the followup concentration data were not complete, mostly due to patients declining to schedule follow-up visits, at least one follow-up blood sample from each patient was obtained during the follow-up period.

The patients were divided into two groups according to their 25(OH)D status at diagnosis as follows: a deficient group ( $<20 \mathrm{ng} / \mathrm{ml}$ ) or a non-deficient group ( $\geq 20 \mathrm{ng} / \mathrm{ml}$ ). During the follow-up period, patients were categorized into the four following groups according to alterations in their 25(OH)D status: persistently deficient (deficient state at diagnosis and at follow-up evaluations), improved (deficient state at diagnosis and non-deficient state at follow-up evaluations), deteriorated (non-deficient state at diagnosis and deficient state at follow-up evaluations) and persistently non-deficient (non-deficient state at diagnosis and at follow-up evaluations). Confounders

We collected the data for potential confounders with known and suspected prognostic factors of breast cancer, including age at diagnosis, body-mass index (BMI), $\mathrm{T}$ stage, $\mathrm{N}$ stage, the stage of cancer based on the $7^{\text {th }}$ american joint committee on cancer (AJCC), lymphatic invasion (LI), vascular invasion (VI), Ki-67, histologic grade $(\mathrm{HG})$ and the status of cancer treatment, such as radiotherapy, chemotherapy and hormonal therapy, as well as tumor characteristics including the expression of estrogen receptor (ER), progesterone receptor (PR) and human epidermal growth factor 2 (HER2) receptor. Fluorescence in situ hybridization (FISH) was unavailable during most of the study period. Therefore, we used immunohistochemical staining to classify the patients. A patient was considered ER- and PR-positive if $1 \%$ or more of the tumor was positively stained. An immunohistochemical staining score of $3+$ for HER2 was considered positive and a HER2 score of $2+$ was considered negative. The season when the blood sample at diagnosis was obtained was defined as follows: Spring, February-April; Summer, May-July; Autumn, AugustOctober; and Winter, November-January.

\section{Statistical analysis}

We evaluated the association between the 25(OH)D status and the patients' disease-free survival (DFS), breast cancer-specific survival (BCSS) and overall survival (OS). DFS was defined as the period from surgery to the date of the first locoregional recurrence, distant metastasis, death from any cause or the date of the last follow-up. BCSS was defined as the period from the date of breast cancer diagnosis until the date of breast cancer-related death or the date of the last follow-up. OS was defined 
as the period from the date of breast cancer diagnosis until the date of death (from any cause) or the date of the last follow-up. An independent t-test and chi-squared test were used to evaluate the significant differences between the clinicopathological features of the groups. The survival curves were obtained using the Kaplan-Meier method and log-rank tests were employed to compare the survival curves. Univariate and multivariate analyses were conducted using Cox's proportional hazard regression model to assess the independent prognostic significance of various confounders and hazard ratios (HRs) and 95\% confidence intervals (95\% CIs) were estimated for each variable. Age at diagnosis (years) was used as the time metric for all regression analysis and the multivariate models were adjusted for age; BMI; T stage; $\mathrm{N}$ stage; ER, PR and HER2 expression; chemotherapy; and lymphatic invasion. We tested and confirmed non-violation of the proportionality assumption based on Schoenfeld residuals. We conducted the assessments of effect modification by stratified analyses to examine whether the association between $25(\mathrm{OH}) \mathrm{D}$ status and survival varied by age and disease stage and heterogeneity between groups was tested by adding a multiplicative interaction term to the model and by using likelihood ratio tests for interactions. All statistical tests were two-sided and the statistical significance was set at $\mathrm{p}<0.05$. All statistical analyses were performed using SPSS version 12.0 (SPSS, Chicago, IL, USA).

\section{Results}

Association of the 25(OH)D status at diagnosis with tumor characteristics

The mean age at diagnosis was $49.61 \pm 10.17$ years and the mean serum $25(\mathrm{OH}) \mathrm{D}$ concentration at diagnosis was $33.53 \pm 17.87 \mathrm{ng} / \mathrm{ml}$ (range: $2.6-100.8 \mathrm{ng} / \mathrm{ml}$ ). A total of 118 $(25.2 \%)$ patients were classified as $25(\mathrm{OH}) \mathrm{D}$-deficient at diagnosis and the mean serum $25(\mathrm{OH}) \mathrm{D}$ concentration was $12.96 \pm 4.16 \mathrm{ng} / \mathrm{ml}$. Moreover, 351 (74.8\%) patients were classified as $25(\mathrm{OH}) \mathrm{D}$ non-deficient at diagnosis with a mean serum $25(\mathrm{OH}) \mathrm{D}$ concentration of $40.44 \pm 15.19 \mathrm{ng} /$ $\mathrm{ml}$. Table 1 presents the baseline characteristics of the $25(\mathrm{OH}) \mathrm{D}$ study population.

There was a significant difference in several characteristics between the two groups, which were as follows: PR positivity, chemotherapy, radiotherapy and follow-up duration. However, no significant differences were observed between the $25(\mathrm{OH}) \mathrm{D}$ status at diagnosis and BMI or cancer stage.

\section{Associations between the 25(OH)D status at diagnosis} and prognosis

Of the 469 breast cancer patients studied, 32 (6.8\%) patients experienced locoregional recurrence or distant metastasis and $26(5.5 \%)$ patients died during the followup period, including $22(4.7 \%)$ patients who died of breast cancer. The median duration of follow-up for the entire cohort was $85.79 \pm 31.01$ months, which was significantly longer in the $25(\mathrm{OH}) \mathrm{D}$ non-deficient group $(89.03 \pm 30.01$ months) compared with the $25(\mathrm{OH}) \mathrm{D}$-deficient group (76.16 \pm 32.05 months).
Figure 1 shows the association between the $25(\mathrm{OH})$ $\mathrm{D}$ status at diagnosis and survival. In the entire study population, only DFS showed a trend toward a poorer survival in the $25(\mathrm{OH}) \mathrm{D}$-deficient group compared with the $25(\mathrm{OH}) \mathrm{D}$ non-deficient group $(\mathrm{p}=0.052)$. However,
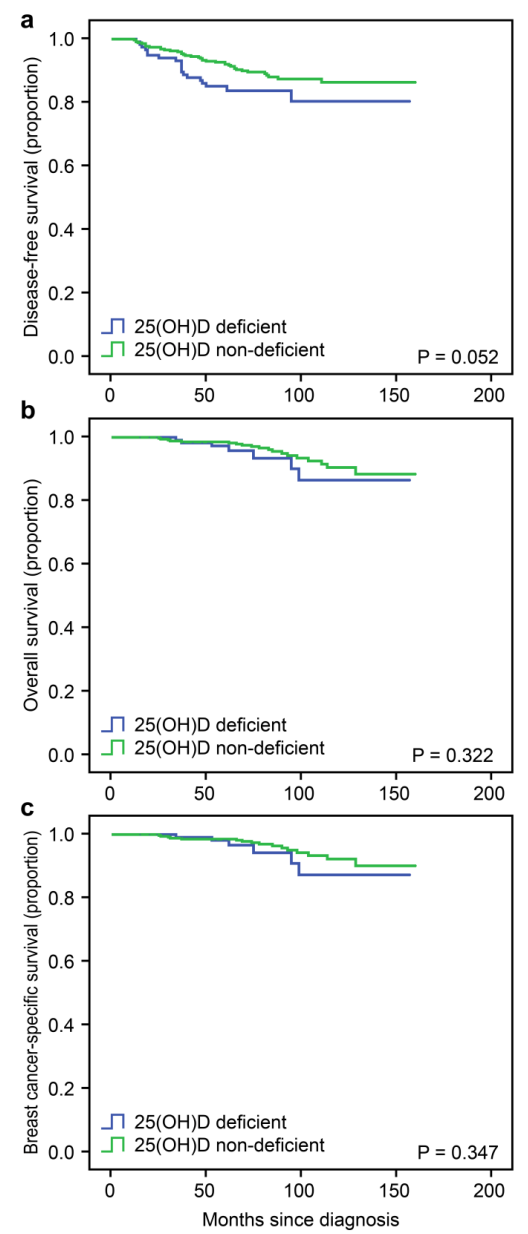

Figure 1. Association Between the 25(OH)D Status at Diagnosis and Survival. (a) disease-free survival (b) overall survival (c) breast cancer-specific survival
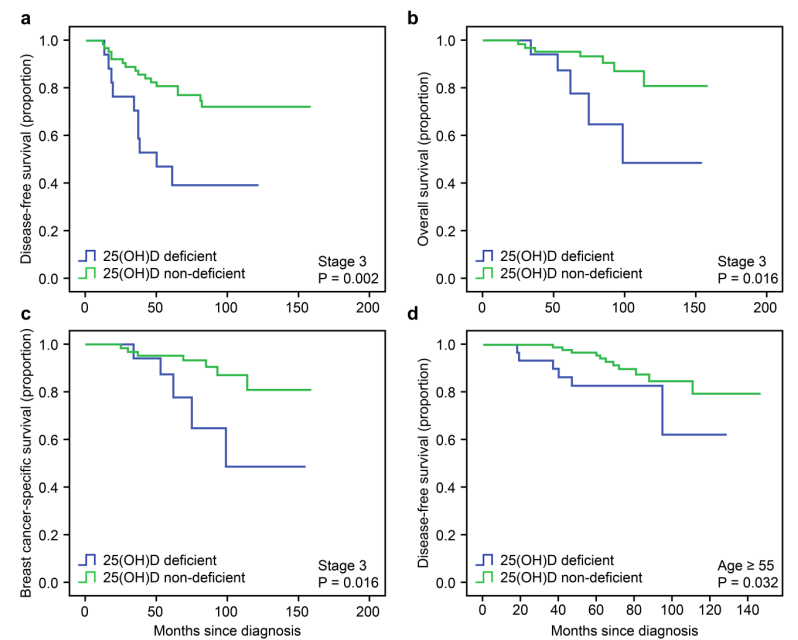

Figure 2. Association Between the 25(OH)D Status at Diagnosis and Survival After Stratification Based on the Stage and Patient Age. (a) disease-free survival in stage 3 patients (b) overall survival in stage 3 patients (c) breast cancerspecific survival in stage 3 patients (d) disease-free survival in patients with age $\geq 55$ 
Table 1. Correlation Between the IER3 Expression and Clinicopathological Factors in 62 PHC P atients

\begin{tabular}{|c|c|c|c|c|c|}
\hline & & Total & Deficient $(<20 \mathrm{ng} / \mathrm{ml})$ & Non-deficient $(\geq 20 \mathrm{ng} / \mathrm{ml})$ & $\mathrm{p}$ value \\
\hline & & No. $(\%)$ & No. $(\%)$ & No. $(\%)$ & \\
\hline \multirow[t]{2}{*}{ Age } & $<55$ & $343(73.1 \%)$ & $87(73.7 \%)$ & $256(72.9 \%)$ & 0.866 \\
\hline & $\geq 55$ & $126(26.9 \%)$ & $31(26.3 \%)$ & $95(27.1 \%)$ & \\
\hline \multirow[t]{3}{*}{ BMI } & $\leq 25$ & $268(57.1 \%)$ & $72(61.0 \%)$ & $196(55.8 \%)$ & 0.506 \\
\hline & $25-30$ & $176(37.5 \%)$ & $39(33.0 \%)$ & $137(39.0 \%)$ & \\
\hline & $>30$ & $25(5.4 \%)$ & $7(6.0 \%)$ & $18(5.2 \%)$ & \\
\hline \multirow[t]{3}{*}{ T stage } & 1 & $204(43.4 \%)$ & $55(46.6 \%)$ & $149(42.5 \%)$ & 0.347 \\
\hline & 2 & $237(50.5 \%)$ & $59 \quad(50 \%)$ & $178(50.7 \%)$ & \\
\hline & 3 & $28(6.1 \%)$ & $4(3.4 \%)$ & $24(6.8 \%)$ & \\
\hline \multirow[t]{4}{*}{$\mathrm{N}$ stage } & 0 & $291(62.0 \%)$ & $75(63.5 \%)$ & $216(61.5 \%)$ & 0.389 \\
\hline & 1 & $103(21.9 \%)$ & $27(22.9 \%)$ & $76(21.7 \%)$ & \\
\hline & 2 & $43(9.1 \%)$ & $12(10.2 \%)$ & $31 \quad(8.8 \%)$ & \\
\hline & 3 & $32(6.8 \%)$ & $4(3.4 \%)$ & $28 \quad(8.0 \%)$ & \\
\hline \multirow[t]{3}{*}{ AJCC stage } & 1 & $152(32.4 \%)$ & $41(34.8 \%)$ & $111(31.6 \%)$ & 0.6 \\
\hline & 2 & $236(50.3 \%)$ & $60(50.8 \%)$ & $176(50.2 \%)$ & \\
\hline & 3 & $81(17.3 \%)$ & $17(14.4 \%)$ & $64(18.2 \%)$ & \\
\hline \multirow[t]{2}{*}{ Estrogen receptor } & Positive & $246(52.4 \%)$ & $59 \quad(50 \%)$ & $187(53.3 \%)$ & 0.538 \\
\hline & Negative & $223(47.5 \%)$ & $59 \quad(50 \%)$ & $164(46.7 \%)$ & \\
\hline \multirow[t]{2}{*}{ Progesteron receptor } & Positive & $244(52.0 \%)$ & $81(68.6 \%)$ & $163(46.4 \%)$ & $<0.001$ \\
\hline & Negative & $225(48.0 \%)$ & $37(31.4 \%)$ & $188(53.6 \%)$ & \\
\hline \multirow[t]{3}{*}{ HER2 receptor } & Positive & $59(12.6 \%)$ & $10(8.5 \%)$ & $49(14.0 \%)$ & 0.12 \\
\hline & Negative & $406(86.8 \%)$ & $107(90.7 \%)$ & $299(85.2 \%)$ & \\
\hline & Unknown & $4 \quad(0.8 \%)$ & $1 \quad(0.8 \%)$ & $3(0.8 \%)$ & \\
\hline \multirow[t]{3}{*}{ Ki-67 } & $\leq 10 \%$ & $188(40.0 \%)$ & $55(46.6 \%)$ & $133(37.9 \%)$ & 0.234 \\
\hline & $>10 \%$ & $153(32.6 \%)$ & $36(30.5 \%)$ & $117(33.3 \%)$ & \\
\hline & Unknown & $128(27.4 \%)$ & $27(22.9 \%)$ & $101(28.8 \%)$ & \\
\hline \multirow[t]{3}{*}{ Lymphatic invasion } & Positive & $122(26.0 \%)$ & $30(25.4 \%)$ & $92(26.2 \%)$ & 0.469 \\
\hline & Negative & $286(61.0 \%)$ & $61(51.7 \%)$ & $225(64.1 \%)$ & \\
\hline & Unknown & $61(13.0 \%)$ & $27(22.9 \%)$ & $34 \quad(9.7 \%)$ & \\
\hline \multirow[t]{3}{*}{ Vascular invasion } & Positive & $8(1.7 \%)$ & $3(2.6 \%)$ & $5(1.4 \%)$ & 0.287 \\
\hline & Negative & $400(85.3 \%)$ & $87(73.7 \%)$ & $313(89.2 \%)$ & \\
\hline & Unknown & $61(13.0 \%)$ & $28(23.7 \%)$ & $33(9.4 \%)$ & \\
\hline \multirow[t]{4}{*}{ Histologic grade } & 1 & $52(11.1 \%)$ & $12(10.2 \%)$ & $40(11.4 \%)$ & 0.914 \\
\hline & 2 & $123(26.2 \%)$ & $30(25.4 \%)$ & $93(26.5 \%)$ & \\
\hline & 3 & $84(17.9 \%)$ & $22(18.6 \%)$ & $62(17.7 \%)$ & \\
\hline & Unknown & $210(44.8 \%)$ & $54(45.8 \%)$ & $156(44.4 \%)$ & \\
\hline \multirow[t]{2}{*}{ Chemotherapy } & Yes & $301(64.2 \%)$ & $65(55.1 \%)$ & $236(67.2 \%)$ & 0.017 \\
\hline & No & $168(35.8 \%)$ & $53(44.9 \%)$ & $115(32.8 \%)$ & \\
\hline \multirow[t]{2}{*}{ Radiotherapy } & Yes & $273(58.2 \%)$ & $78(66.1 \%)$ & $195(55.6 \%)$ & 0.044 \\
\hline & No & $196(41.8 \%)$ & $40(33.9 \%)$ & $156(44.4 \%)$ & \\
\hline \multirow[t]{2}{*}{ Hormone therapy } & Yes & $353(75.3 \%)$ & $93(78.8 \%)$ & $260(74.1 \%)$ & 0.302 \\
\hline & No & $116(24.7 \%)$ & $25(21.2 \%)$ & $91(25.9 \%)$ & \\
\hline \multicolumn{6}{|c|}{ Follow-up duration (months) Season of blood draw at diagnosis } \\
\hline & & $85.79 \pm 31.01$ & $76.16 \pm 32.05$ & $89.03 \pm 30.01$ & $<0.001$ \\
\hline & Spring & $116(24.7 \%)$ & $27(22.9 \%)$ & $89(25.4 \%)$ & 0.092 \\
\hline & Summer & $117(24.9 \%)$ & $28(23.7 \%)$ & $89(25.4 \%)$ & \\
\hline & Autumn & $149(31.8 \%)$ & $32(27.1 \%)$ & $117(33.3 \%)$ & \\
\hline & Winter & $87(18.6 \%)$ & $31(26.3 \%)$ & $56(15.9 \%)$ & \\
\hline
\end{tabular}

*SD standard deviation; BMI body mass index; AJCC American joint committee on cancer

after stratification based on tumor staging, the $25(\mathrm{OH})$ D-deficient group with advanced-stage disease showed significantly poorer survival for DFS $(\mathrm{p}=0.002)$, OS $(\mathrm{p}=0.016)$ and BCSS $(\mathrm{p}=0.016)$ compared with the non-deficient group (Figure 2). Similarly, the 25(OH) D-deficient group of older aged patients showed significantly poorer survival for DFS $(\mathrm{p}=0.032)$ compared with the $25(\mathrm{OH}) \mathrm{D}$ non-deficient group.

Association of alterations in the 25(OH)D status and prognosis

We determined the patient serum 25(OH)D concentrations annually until 4 years after diagnosis and investigated the association between alterations in the $25(\mathrm{OH}) \mathrm{D}$ status during the follow-up period and survival. Regarding DFS, no statistically significant association was observed between an altered 25(OH)D status and survival until 4 years of follow-up after diagnosis. However, a trend in BCSS was observed, where the persistently non-deficient group and the improved group showed better survival compared with the other two groups at the 1-year follow-up ( $\mathrm{p}=0.051)$ (Figure 3). Moreover, for OS, a significantly better survival was evident in the persistently non-deficient group and the improved group compared with the other two groups at the 1-year followup $(\mathrm{p}=0.014)$. 


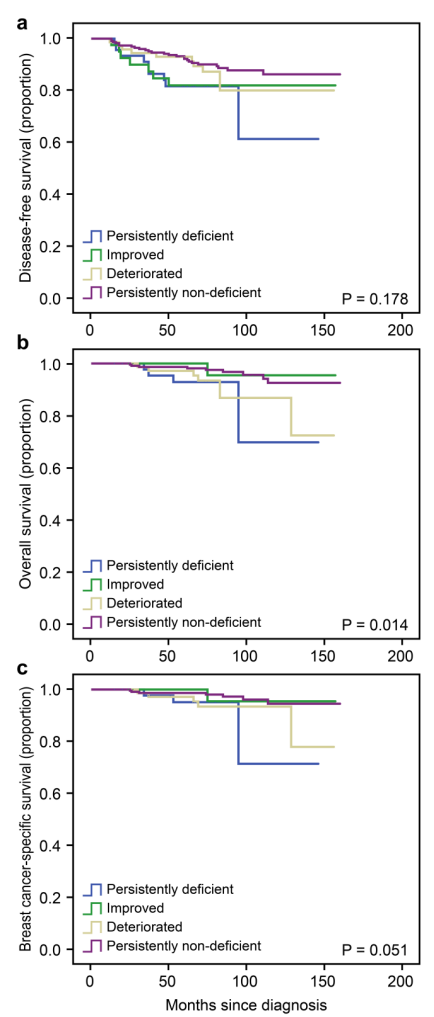

Figure 3. Association Between Alterations in the 25(OH)D Status at the 1-Year Follow-Up and Survival. (a) disease-free survival (b) overall survival (c) breast cancerspecific survival

Univariate and multivariate analyses for survival

We conducted univariate and multivariate analyses to determine the risk factors that can affect survival. The univariate analysis showed that the $\mathrm{T}$ stage, $\mathrm{N}$ stage, AJCC stage, LI, chemotherapy and alterations in the $25(\mathrm{OH}) \mathrm{D}$ status at the 1-year follow-up were significantly associated with DFS, OS and BCSS. Subsequently, the multivariate analysis showed that the $25(\mathrm{OH}) \mathrm{D}$ status at diagnosis was an independent prognostic indicator for DFS and that an alteration in the $25(\mathrm{OH}) \mathrm{D}$ status at the 1-year follow-up was similarly an independent prognostic indicator for DFS, OS and BCSS (Table 2).

\section{Discussion}

In this study, we observed a significant association between alterations in the 25(OH)D status during a 4-years follow-up after 
diagnosis and breast cancer patient survival. To our knowledge, this study is the first to investigate alterations in the $25(\mathrm{OH}) \mathrm{D}$ status during the follow-up period as a prognostic predictor for breast cancer patients. Furthermore, we confirmed the association between the 25(OH)D status at diagnosis and breast cancer patient survival in detail by using stage and age-based stratifications.

Although many studies have been performed to date, a standard optimal $25(\mathrm{OH}) \mathrm{D}$ concentration is still under debate. Several reports from Western countries suggested that the optimal serum $25(\mathrm{OH}) \mathrm{D}$ concentration is $>30 \mathrm{ng} /$ ml (Holick., 2007; Peppone et al., 2011; Bilinski et al., 2013), but geographical and sociocultural differences can and do exist between Western and Asian populations. $\mathrm{McCullough}$ et al. reported a relatively low serum 25(OH)D concentration in Asian people compared with Western people, most likely due to the low incidence of supplement use, the lack of food fortification and a low amount of sunlight exposure (McCullough et al., 2010). Moreover, Manson et al. mentioned that a serum 25(OH) D concentration of $>20 \mathrm{ng} / \mathrm{ml}$ was adequate to maintain bone health in $97.5 \%$ of North Americans (Manson et al., 2011). Thus, in our study, we established a cut-off value for the serum $25(\mathrm{OH}) \mathrm{D}$ concentration of $20 \mathrm{ng} / \mathrm{ml}$. However, additional research is needed to determine the optimal value of the serum $25(\mathrm{OH}) \mathrm{D}$ concentration that prudently considers the various possible confounding factors.

To date, several studies have shown worse DFS in breast cancer patients with a low $25(\mathrm{OH}) \mathrm{D}$ concentration at diagnosis. In 2011, Kim et al. reported that a worse DFS occurred in the low $25(\mathrm{OH}) \mathrm{D}$ concentration $(<20 \mathrm{ng} / \mathrm{ml})$ group compared with the high $25(\mathrm{OH}) \mathrm{D}$ concentration $(\geq 30 \mathrm{ng} / \mathrm{ml})(\mathrm{HR}=3.97$; 95\% CI 1.77-8.91) (Kim et al., 2011). Likewise, in 2012, Hatse et al. reported a worse DFS for postmenopausal breast cancer patients with a low 25(OH)D concentration ( $\leq 30 \mathrm{ng} / \mathrm{ml})$ compared with patient with a high $25(\mathrm{OH}) \mathrm{D}$ concentration $(>30 \mathrm{ng} / \mathrm{ml})$ (relapse rate of $7.8 \%$ versus $5.6 \%$, respectively, after 4.7 years of follow-up) (Hatse et al., 2012). These reports did not apply stage stratification to the analysis of DFS, however; the low $25(\mathrm{OH}) \mathrm{D}$ concentration groups of both studies included patients with significantly more advanced $\mathrm{T}$ - or $\mathrm{N}$-stage disease which might have skewed the survival analysis results. In our study, after stage- and age-based stratifications, the $25(\mathrm{OH}) \mathrm{D}$ deficient $(<20 \mathrm{ng}$ / $\mathrm{ml}$ ) group showed a significantly worse DFS, OS or BCSS compared with the non-deficient ( $\geq 20 \mathrm{ng} / \mathrm{ml}$ ) group with advanced-stage (stage 3 ) disease and the older ( $\geq 55$ years) patients. The explanation for these results is unclear; however, it is plausible that the low-estrogen environment of older aged women or the relatively increased risk of post-therapeutic micro-residual disease in advanced-stage breast-cancer patients may lead to an enhanced prognostic impact of the $25(\mathrm{OH}) \mathrm{D}$ status.

Our study showed a significant association between alteration in the $25(\mathrm{OH}) \mathrm{D}$ status at the 1-year followup and OS and BCSS. Clinically, the serum 25(OH)D status can be greatly affected within 1-year after surgery by adjuvant chemotherapy and by drastic lifestyle changes. Therefore, based on our findings, maintaining an optimal serum $25(\mathrm{OH}) \mathrm{D}$ status within 1 year after diagnosis is important for improving patient's survival. Interestingly, the improved group and the persistently non-deficient group showed better survival compared with the persistently deficient group. This result suggested that even if a patient's $25(\mathrm{OH}) \mathrm{D}$ status at diagnosis was not optimal, an opportunity to improve the patient's survival arises by correcting their $25(\mathrm{OH}) \mathrm{D}$ status through vitamin D supplementation or appropriate life-style modifications. Although the institute of medicine and the endocrine society recommend 600-800 IU/day of vitamin $\mathrm{D}$ supplementation for healthy women to maintain bone health and optimal calcium homeostasis (Institute of Medicine., 2010; Holick., 2011), no clear consensus about a reasonable supplementation dose for breast cancer patients has emerged. For this reason, we emphasize the necessity of further studies to investigate this subject.

Similar to previous studies, our study had several limitations. First, our results had limited power because of the incomplete follow-up data for $25(\mathrm{OH}) \mathrm{D}$ measurement, including the season of blood sampling for the follow-up measurements. This limitation most likely resulted from the retrospective study design. Second, the sample size and incidence of survival events in our study were relatively small. Finally, we were not able to collect data about the patients' vitamin D supplementation, amount of physical activity and amount of sunlight exposure, all of which can influence an individual's 25(OH)D status. However, we expect that these limitations can be overcome by a larger, prospective study and thorough collection of clinical data.

In conclusion, our results demonstrate that the $25(\mathrm{OH})$ D status at diagnosis and at the 1-year follow-up is significantly associated with the survival of breast cancer patients. These findings may provide the grounds to justify clinical efforts to maintain and improve a patient's $25(\mathrm{OH}) \mathrm{D}$ status through vitamin D supplementation or lifestyle modifications, not only before diagnosis but also after surgery, to enhance breast cancer patients' survival particularly in advanced-stage cancer and older patients. To confirm our results, a more properly designed, larger scale study is urgently warranted.

\section{References}

Alipour S, HadjiM, Hosseini L, et al (2014) Levels of serum 25-hydroxy-vitamin $\mathrm{D}$ in benign and malignant breast masses. Asian Pac J Cancer Prev, 15, 129-32

Bikle D (2009) Nonclassic actions of vitamin D. J Clin Endocrinol Metab, 94, 26-34

Bilinski K, Boyages J (2013) Association between 25-hydroxyvitamin $\mathrm{D}$ concentration and breast cancer risk in an Australian population: an observational case-control study. Breast Cancer Res Treat, 137, 599-607

Carlberg C (2003) Current understanding of the function of the nuclear vitamin D receptor in response to its natural and synthetic ligands. Recent Results Cancer Res, 164, 29-42

Crew KD, Gammon MD, Steck SE, et al (2009) Association between plasma 25-hydroxyvitamin D and breast cancer risk. Cancer Prev Res, 2, 598-604

Goodwin PJ, Ennis M, Pritchard KI, Koo J, Hood N (2009) Prognostic effects of 25-hydroxyvitamin D levels in early breast cancer. J Clin Oncol, 27, 3757-63

Hatse S, Lambrechts D, Verstuyf A, et al (2012) Vitamin D 
status at breast cancer diagnosis: correlation with tumor characteristics, disease outcome and genetic determinants of vitamin D insufficiency. Carcinogenesis, 33, 1319-26

Heaney RP, Davies KM, Chen TC, Holick MF, Barger-Lux MJ (2003) Human serum 25-hydroxycholecalciferol response to extended oral dosing with cholecalciferol. Am J Clin Nutr, 77, 204-10

Holick MF (2006) Vitamin D: its role in cancer prevention and treatment. Prog Biophys Mol Biol, 92, 49-59

Holick MF (2007) Vitamin D deficiency. N Engl J Med, 357, 266-81

Holick MF (2009) Vitamin D status: measurement, interpretation and clinical application. Ann Epidemiol, 19, 73-8

Holick MF, Binkley NC, Bischoff-Ferrari HA, et al (2011) Evaluation, treatment and prevention of vitamin D deficiency: an endocrine society clinical practice guideline. J Clin Endocrinol Metab, 96, 1911-30

Institute of Medicine (2010) Dietary Reference Intakes for Calcium and Vitamin D. The National Academies Press, Washington

Iqbal SJ (1994) Vitamin D metabolism and the clinical aspects of measuring metabolites. Ann Clin Bio chem, 31, 109-24

Jacobs ET, Alberts DS, Foote JA, et al (2008) Vitamin D insufficiency in southern Arizona. Am J Clin Nutr, 87, 608-13

Kermani IA, Kojidi HT, Gharamaleki JV, et al (2011) Association of serum level of 25 hydroxy-vitamin D with prognostic factors for breast cancer. Asian Pac J Cancer Prev, 12, 1381-4

Kim ML, Il Kang M, Won Oh K, et al (2010) The association of serum vitamin D level with presence of metabolic syndrome and hypertension in middle-aged Korean subjects. Clin Endocrinol, 73, 330-8

Kim HJ, Lee YM, Ko BS, et al (2011) Vitamin D deficiency is correlated with poor outcomes in patients with luminal-type breast cancer. Ann Surg Oncol, 18, 1830-6

Kim HJ, Koh BS, Yu JH, et al (2014) Changes in serum hydroxyvitamin D levels of breast cancer patients during tamoxifen treatment or chemotherapy in premenopausal breast cancer patients. Eur J Cancer, 50, 1403-11

Lee ES, Ahn J, Patk HM (2009) Serum vitamin D status of Korean postmenopausal women during the winter months. Asia Pac J ClinNutr, 18, 29-33

Manson JE, Mayne ST, Clinton SK (2011) Vitamin D and prevention of cancer-ready for prime time? N Engl J Med, 364, 1385-7

McCullough ML, Weinstein SJ, Freedman DM, et al (2010) Correlates of circulating 25-hydroxyvitamin D: cohort consortium vitamin d pooling project of rarer cancers. $A M$ J Epidemiol, 172, 21-35

Mousavi-Jarrrahi SH, Kasaeian A, Mansori K, et al (2013) Addressing the younger age at onset in breast cancer patients in Asia: an age-period-cohort analysis of fifty years of quality data from the international agency for research on cancer. ISRN Oncol, 2013, 429862

Palmieri C, MacGregor T, Girgis S, Vigushin D (2006) Serum 25-hydroxyvitamin D levels in early and advanced breast cancer. J Clin Pathol, 59, 1334-6

Peppone LJ, Huston AJ, Reid ME, et al (2011) The effect of various vitamin $\mathrm{D}$ supplementation regimens in breast cancer patients. Breast Cancer Res Treat, 127, 171-7

Shi L, Nechuta S, Gao YT, et al (2014) Correlates of 25-hydroxyvitamin $\mathrm{D}$ among Chinese breast cancer patients. PLoS One, 9, 86467

Vance V, Campbell S, McCargar L, Mourtzakis M, Hanning R (2014) Dietary changes and food intake in the first year after breast cancer treatment. Appl Physiol Nutr Metab, 39, 707-14

Villaseñor A, Ballard-Barbash R, Ambs A, et al (2013)
Associations of serum 25-hydroxyvitamin D with overall and breast cancer-specific mortality in a multiethnic cohort of breast cancer survivors. Cancer Causes Control, 24, 759-67 